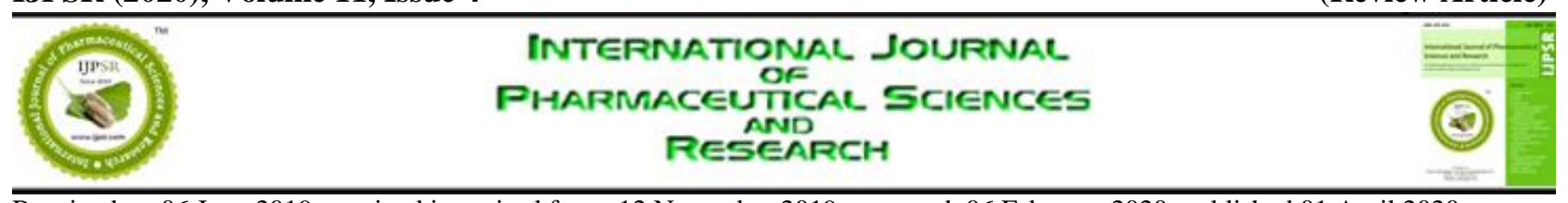

Received on 06 June 2019; received in revised form, 12 November 2019; accepted, 06 February 2020; published 01 April 2020

\title{
FAST DISSOLVING TABLETS: A REVIEW
}

\author{
Ramakant Joshi ${ }^{*}$, Navneet Garud and Wasim Akram
}

Department of Pharmaceutics, School of Studies in Pharmaceutical Sciences, Jiwaji University, Gwalior 474011, Madhya Pradesh, India.

\section{Keywords:}

Mouth dissolving tablets, Manufacturing technology, Superdisintegrants, Evaluation

\section{Correspondence to Author: \\ Ramakant Joshi}

Assistant Professor,

Department of Pharmaceutics,

School of Studies in Pharmaceutical

Sciences, Jiwaji University, Gwalior -

474011, Madhya Pradesh, India.

E-mail: joshiram78@gmail.com

\begin{abstract}
For treatment or management of diseases, oral delivery is giving much more attention from the ancient decade. A new concept in oral delivery is mouth dissolving tablets (MDTs) are widely accepted nowadays. Mouth dissolving tablets are solid dosage forms which, when placed in the mouth, disintegrate, dissolve and release active agent within a few minutes without the need for water. It has more significance to geriatric, Pediatric, bedridden patients because they have a problem in swallowing and the patient with dysphasia. It is more useful for the traveler and busy patients who don't have easy access to water. Mouth dissolving tablets are prepared by various technologies with the aid of superdisintegrants. Mouth dissolving tablets are more reliable than conventional dosage forms like tablets, capsules because of better patient compliance. The advancement in this field allows the development of an economic and better way of disease management with avoidance of several problems related to the other delivery systems.
\end{abstract}

INTRODUCTION: The oral passage of medicament administration for illness is measured as the most conventional route. Tablet is a commonly prescribed dosage form as of its accessibility in terms of self-administration, solidity and simplicity in development. Patients particularly pediatric and geriatric, often experience trouble in swallowing conventional tablets and this problem may prove worst during the traveling conditions due to the non-availability or restricted availability of water. These problems of conventional dosage forms can be encountered by the development of mouth dissolving tablets ${ }^{1,2,3}$.

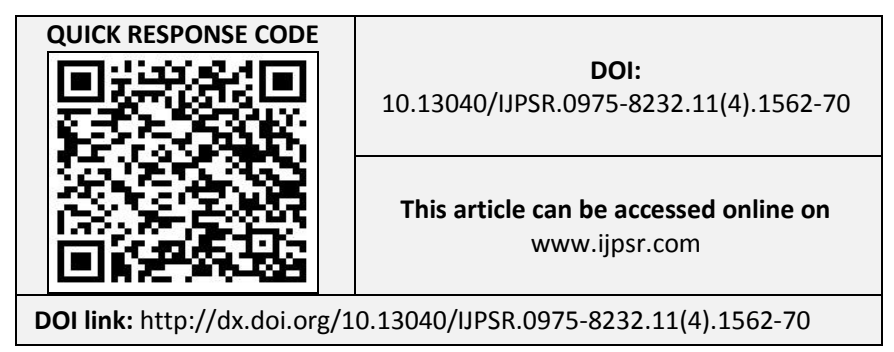

These tablets disintegrate in the mouth within a very short span i.e. 20-30 sec and comes in contact with saliva resulting in the therapeutic action of active agent ${ }^{4,5}$. Mouth dissolving tablets show better patient compliance and acceptance with improved bioavailability, efficacy and biopharmaceutical properties, in contrast to conventional tablets ${ }^{6}$.

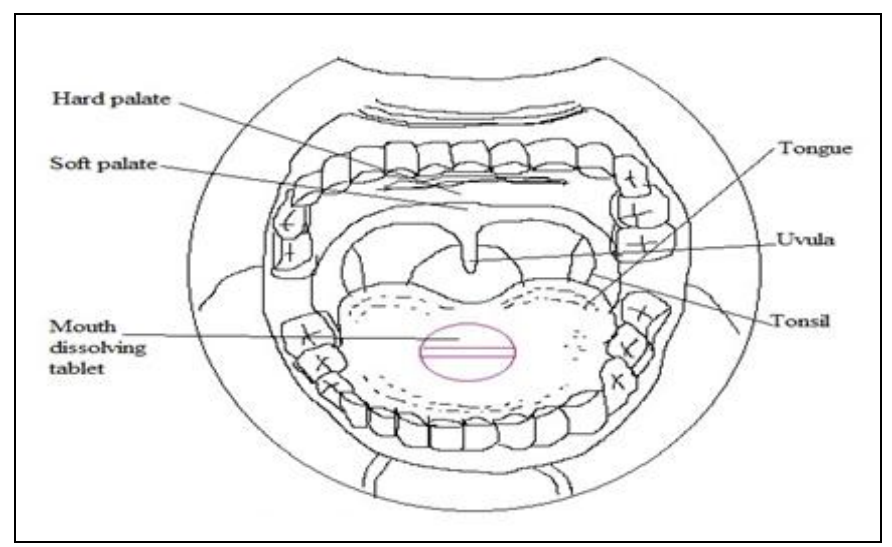

FIG. 1: ADMINISTRATION OF MOUTH DISSOLVING TABLETS 
Mouth dissolving phenomenon is a very supportive route for life-threating diseases patients like nervous illness, radioactivity therapy, Parkinson's disease, AIDS which face the dysphasia condition 7. Administration of new dosage formulations like effervescent tablets, dry syrups to these patients involves distress due to the necessary intake of water. But mouth dissolving tablets do not require water ingestion for dosage administration and hence enhance patient compliance.

There are various synonyms for mouth dissolving tablets like orally disintegrating tablets, fastdissolving tablets, fast melting tablets etc.

The European pharmacopeia states that "orodisperse" is the tablet that can disintegrate very quickly in mouth without the need of water ${ }^{8}$.

Advantages of Mouth Dissolving Tablets: Mouth dissolving tablets are absorbed by the pre gastric area i.e. pharynx, esophagus so this will leads to produce the quick onset of action ${ }^{9}, 10$. This may result in the enhancement of bioavailable of an active pharmaceutical agents by dose minimization and clinical effectiveness with low risk of adverse effects ${ }^{11}$. Mouth dissolving tablets formulated with good taste-masking agents may increase patient acceptance of drugs with unacceptable taste particularly in pediatric patients. Another comfort is added to avoid the blocking of an oral route by use of conventional dosage form ${ }^{12,13}$.

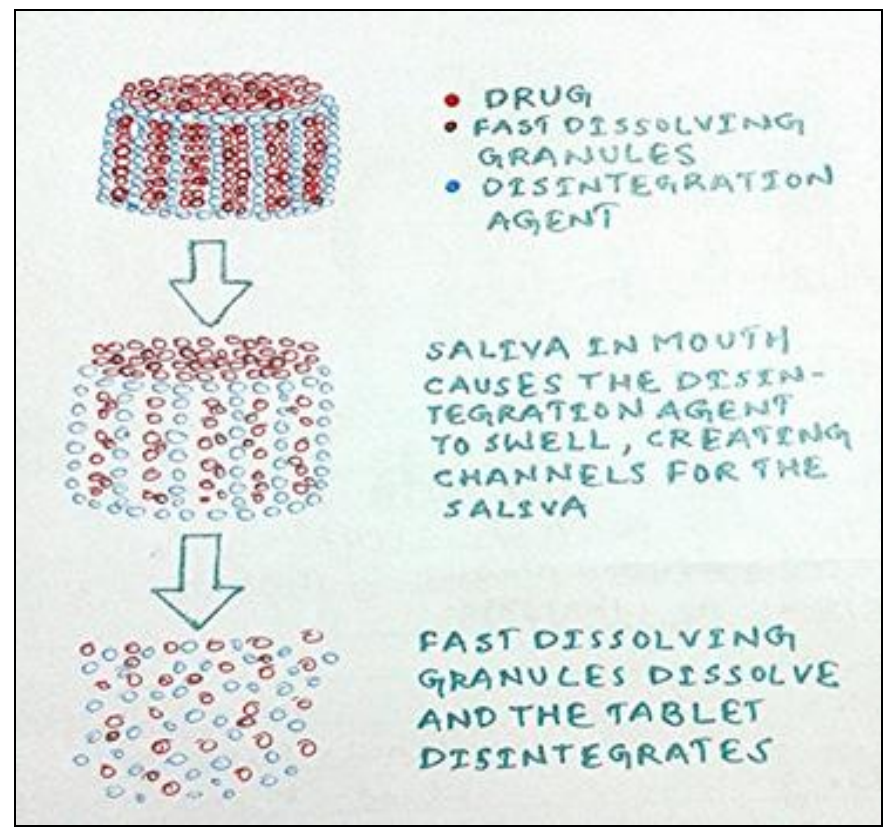

FIG. 2: DISINTEGRATION OF MOUTH DISSOLVING TABLETS

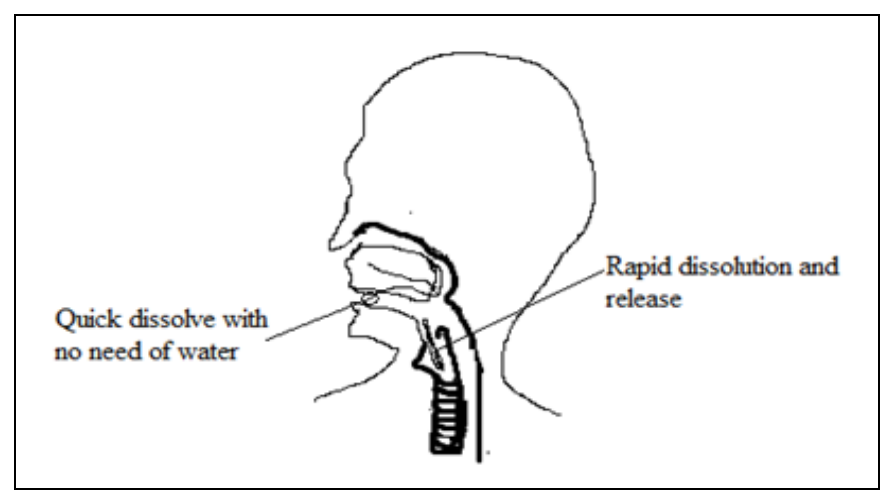

FIG. 3: DISSOLUTION AND RELEASE MECHANISM OF MOUTH DISSOLVING TABLETS

Ideal Properties of Drug for Development of Mouth Dissolving Tablets: In the development of MDTs various factors keeps for selecting the drug candidate.

$>$ Those drugs which are able to diffuse into epithelial of upper GIT $(\log \mathrm{P}>2)$.

$>$ Short half-life drugs with frequent dosing.

$>$ Drugs that produce toxic metabolites by firstpass metabolism.

$>$ Sustained and controlled release drugs are unsuitable for MDTs.

$>$ Very bitter drugs with unacceptable taste are unsuitable for MDTs ${ }^{14}$.

\section{Potential Drug Candidates for Mouth Dissolving} Tablets:

$>$ Non-steroidal Anti-Inflammatory Drugs: Ketoprofen, Piroxicam, Paracetamol, Rofecoxib, Nimesulide, Ibuprofen.

$>$ Anti-ulcer Drugs: Famotidine, Lansoprazole.

$>$ Antidepressants Drugs: Mitraxepine, Fluoxetine.

$>$ Antiparkinsonian Drugs: Selegiline.

$>$ Antimigrane Drugs: Sumatriptan, Rizatriptan benzoate, Zolmitriptan.

$>$ Anti-histaminic Drugs: Loratadine, Diphenhydramine, Meclizine.

Antiemetic Drugs: Ramosetoron $\mathrm{HCl}$, Ondansetron, Baclofen ${ }^{15,16,17 .}$

Mouth Dissolving Phenomenon: In the formulation of mouth dissolving tablets, superdisintegrants pay much more attention. They 
provide fast disintegration by the action of swelling and water absorption in the tablet. The surface of the carrier is wetted by the swelling mechanism of the superdisintegrants, which leads to enhancement of the disintegration of tablets results in higher dissolution occurs ${ }^{18}$.

The performance of functioning superdisintegrants depends on swelling capacity in the dissolution medium and the density of the formed matrix. Higher swelling capacity and density of the matrix lead to a greater level of disintegration ${ }^{19}$.

Mechanisms of Superdisintegrants: They work by four basic mechanisms-

1. Swelling: By this mechanism, certain disintegrating agents (like starch) impart the disintegrating effect upon contact with water, cause the tablet breakdown. e.g. Sodium starch glycolate, Plantago Ovata ${ }^{20}$.

\section{Porosity and Capillary Action (Wicking):}

The disintegration action of some superdisintegrants is by the capillary action and porosity. The disintegrated particles act to enhance porosity which conveys ways for the permeation of fluid into tablets. After that via capillary action or wicking action, the liquid is tired up, this results in inter particulate bonds breakdown and ultimately tablet disintegration. e.g. Crosspovidone, Crosscarmellose ${ }^{21}$.

3. Deformation: When the pressure applied to the starch grains they deformed and when pressure removed they will come into original shape. But when they compressed into tablets they deformed permanently which release their energy when coming in contact with water ${ }^{22}$.

\section{Due to Disintegrating Particle/Particle} Repulsive Forces: This mechanism is associated with non-swell able disintegrants. For that Guyot-Hermann has given particle repulsion theory. According to thatdisintegration electric repulsive forces between particles are responsible for the water. It is believed that no single mechanism is responsible for the action of most disintegrants. But, it is the result of inter-relationships between these major mechanisms ${ }^{23}$.

TABLE 1: LIST OF COMMERCIALLY AVAILABLE SUPERDISINTEGRANTS

\begin{tabular}{|c|c|c|c|c|}
\hline S. no. & Superdisintegrants & Mechanism of action & Properties & Avialable grades \\
\hline 1 & $\begin{array}{l}\text { Cross-linked Alginic } \\
\text { acid }\end{array}$ & $\begin{array}{l}\text { Worked by wicking movement, } \\
\text { prompt bulge upon hydration }\end{array}$ & $\begin{array}{l}\text { Loose cohesion in a } \\
\text { wet and dry medium }\end{array}$ & Alginic acid, Satialgine \\
\hline 2 & Cross-linked PVP & Act by capillary action & $\begin{array}{l}\text { Spongy in nature and } \\
\text { water-insoluble }\end{array}$ & $\begin{array}{l}\text { Kollidon, POlyplasdone, } \\
\text { Crosspovidone, } \\
\text { Crosspovidone } \mathrm{M}\end{array}$ \\
\hline 3 & Cross-linked starch & $\begin{array}{c}\text { In less than } 30 \text { seconds swells } 7- \\
11 \text { folds }\end{array}$ & $\begin{array}{l}\text { Gives sustained release } \\
\text { in a matrix and swells } \\
\text { in three dimensions }\end{array}$ & $\begin{array}{l}\text { Primogel, Sodium starch } \\
\text { glycolate, Explotab }\end{array}$ \\
\hline 4 & $\begin{array}{l}\text { crosslinked polymer } \\
\text { of Polycarboxylic } \\
\text { acids }\end{array}$ & $\begin{array}{l}\text { Very high swelling tendency of } \\
\text { hydration either in contact with } \\
\text { water or G.I. fluids }\end{array}$ & $\begin{array}{l}\text { increases the effective } \\
\text { surface area for the } \\
\text { absorption of the active } \\
\text { substances }\end{array}$ & Kyron T-314 \\
\hline 5 & $\begin{array}{l}\text { Cross-linked } \\
\text { cellulose }\end{array}$ & $\begin{array}{c}\text { Swells } 4 \text { to } 8 \text { folds in less than } \\
10 \text { seconds. Swelling and } \\
\text { wicking }\end{array}$ & $\begin{array}{l}\text { Used in direct } \\
\text { compression or } \\
\text { granulation, swelling is } \\
\text { in two dimension }\end{array}$ & $\begin{array}{c}\text { Croscarmellose, Ac-Di-sol, } \\
\text { Nymce ZSX, primellose, } \\
\text { Solutab, Vivasol }\end{array}$ \\
\hline
\end{tabular}

Manufacturing of Mouth Dissolving Tablets: For the development of MDTs various special technologies employed such as lyophilization, spray drying, direct compression, sublimation, mass extrusion, cotton candy, etc.

Freeze-drying or lyophilization method is frequently considered nowadays. This technique involves freezing of products followed by sublimation, which converts the product into a porous structure that can dissolve easily. A carrier is selected in which the drug is dispersed and the mixture is poured into a preformed blister. These blisters are kept in a tray which is passed through the liquid nitrogen tunnel to freeze the dispersion followed by exposure to the freeze dryer. Aluminum foil is utilized as backing material for the sealing of blisters ${ }^{24}$. 
Zydis technology (ZT), based on the principle of freeze-drying process, is a patented technique for the manufacturing of mouth dissolving tablets ${ }^{25,26}$. Thirteen products are currently available in the market containing various active pharmaceutical agents named Ondansetron, loperamide, piroxicam, rizatriptan, lorazepam, domperidone, oxazepam, olanzapine, and, famotidine etc. which had been manufactured using this technology ${ }^{27}$. To achieve the various formulation goals using this technique different excipients are incorporated which perform various activities. For instance, gelatin is used to provide strength and rigidity for tablets. Matrix crystallinity and hardness are improved by mannitol or sorbitol which is important for enhanced palatability. Glycine play a role in the prevention of shrinking in its packaging during manufacturing or storage. The uniform dispersion of drug particles is achieved by xanthan gum or acacia. Apart from these, preservatives like parabens, permeation enhancers for trans-mucosal permeability like sodium lauryl sulphate, $\mathrm{pH}$ adjusters like citric acid, and the most important excipient flavors and sweeteners are used which improve patient compliance.

The major advantage of this technique resides in fast-melting effect which reflects by very low disintegration time and good mouthfeel. But it relatively expensive and time-consuming and the product is poorly stable and fragile, so the conventional packaging is not suitable ${ }^{28}$. Shoukri et al., [2009] developed the orally disintegrating tablets of nimesulide (NM) by lyophilization method. NM is the drug with poor solubility and poor bioavailability. Orally disintegrating tablets (ODTs) of NM disintegrates within few seconds and showed significantly faster dissolution rates compared to the plain powdered drug and conventional commercial tablet. The developed formulation showed in-vitro disintegration time less than $10 \mathrm{sec}$ and enhanced in-vivo bioavailability up to $60 \%$. In this, they used various disintegration accelerators PEG 400, PEG 4000, PVP K25, PVP K30, PVP K90, Tween 20, Tween 80 etc. in which PVP K90 show very low wetting time $5.53 \mathrm{sec}^{29}$.

In spite of enormous technological developments in the manufacturing of MDTs, direct compression is widely used because it is very economical and simple. The tablet excipients with good micrometric properties like compression, enhanced flow and disintegration effect are used for the direct compression manufacturing process. The disintegration rate is affected by the use of disintegrants which leads to dissolution enhancement in the presence of water-soluble excipients. The incorporation of superdisintegrants has more significance in this process ${ }^{30}$. Superdisintegrants are the key factors for tablet disintegration time. As long as for below significant concentration of superdisintegrants, tablet disintegration time increases with decreased concentration of superdisintegrants and vice versa, remains steady for elevated concentration ${ }^{31}$. Two types of disintegrants are used, first is a disintegrating agent which has high swelling force like- modified cellulose and the second one is the swelling agent like- starch which has low swelling force ${ }^{32}$. Apart from these effervescent agents are used for the evolution of $\mathrm{CO}_{2}$ which works as the disintegrating mechanism used to achieve fast disintegration 33,34 .

This technique contains the incorporation of active pharmaceutical ingredients with polymers like methylcellulose, acrylates etc. in collaboration of tablet excipients such as mannitol, magnesium oxide etc. followed by continuous stirring. These excipients act ac release organizers of active pharmaceutical ingredients from polymers. After that at $50{ }^{\circ} \mathrm{C}$ dried for approximately one hour, then de-lumped and taken up for second time drying on identical temperature, passed it through 8 mesh screen size and further dry it for one hour at $60{ }^{\circ} \mathrm{C}$.

These shaped microparticles, effervescent agents and additional excipients are mixed and compressed into tablets ${ }^{33}$. The taste masking can also be done with the practice of sugar-based excipients like sorbitol, fructose lactitol, maltose etc. These agents are highly hydrophilic nature and impart sweetness so produce pleasant mouth feel ${ }^{34}$. Mizumoto [1996] described two types of saccharides which categorized as one type is highly dissolve such as lactose, mannitol whereas another type contains short dissolution such as maltose ${ }^{35}$.

Singh et al., [2012] developed a Zolmitriptan mouth dissolving tablet using superdisintegrants like kyron T-314, Crosspovidone, Croscarmellose 
sodium, and sodium starch glycolate and combination with a vacuum-drying technique for improved therapeutic efficacy by direct compression technique. The formulation prepared using kyron T-314 exhibited a rapid disintegration time of 35 seconds. In the current market, these mouth dissolving tablets of Zolmitriptan have a rapid onset of action, increased bioavailability and good stability ${ }^{36}$. Jain et al., [2016] developed Flurbiprofen solid dispersion with PEG 6000 and further this was directly compressed to mouth dissolving tablets using superdisintegrants like sodium starch glycolate, cross carmellose sodium and Kyron T-314. The prepared lots of MDTs were characterized for micrometric study, thickness, hardness, weight variation, wetting time, disintegration time, drug content and in-vitro drug release profile.

Among them KT9 formulation containing 4\% Kyron T-314 showed the best results with a wetting time and disintegration time of 28.3 and $38.3 \mathrm{sec}$, respectively. KT9 formulation showed a superior drug release of $99.96 \%$ in comparison to $54.24 \%$ of conventional formulation over a period of $30 \mathrm{~min}$ ${ }^{37}$. Joshi et al., [2018] formulated an active delivery system for the management of hypertension. The Orodispersible tablets (ODTs) containing Telmisartan were developed in order to accomplish enhanced solubility leading to a better bioavailability profile. Different ratios, of Telmisartan and PEG 6000 i.e. 1:1, 1:2, 1:3, 1:4 and 1:5 were selected for the formulation of the ODT system. A batch process was adopted for the preparation of solid dispersion with each combination of drug and polymer and the finally compressed as tablets by direct compression technique. For the preformulation perspective materials were scrutinized on the basis of solubility profile, drug content, Fourier Transform Infrared (FTIR) spectroscopy and Differential scanning calorimetry (DSC). The drug-polymer ratio 1:4 was selected for further compression process.

The prepared batches of ODTs were characterized for micrometric study, thickness, hardness, weight variation, wetting time, disintegration time, drug content and in-vitro drug release profile. The evaluation data for all batches was satisfactory out of them formulation TF3 containing 6\% kyron T314 showed the best results with a value of $29.3 \mathrm{sec}$ and $24.1 \mathrm{sec}$ for wetting and disintegration, respectively. This formulation showed a superior drug release of $99.93 \%$ over a period of $30 \mathrm{~min}^{38}$.

Another technique for MDT manufacturing involves the spray drying process for the production of highly porous, fine powder in the response of rapid evaporation of the solvent. Fast dissolving tablets are manufactured by this technique. In this process support matrix and other components form porous and fine powder is kept in an aqueous solution incorporated with the main constituent and directly tablets are punched ${ }^{39}$. In this process hydrolyzed and un-hydrolyzed gelatin is cast-off as a matrix, bulking agent is mannitol and disintegrants are sodium starch glycolate, Croscarmellose. The dissolution and disintegration phenomenon is enriched by the incorporation of acid or alkaline components like citric acid, sodium bicarbonate respectively. Furthermore, the mixture of excipients was spray-dried to produce a porous powder material subsequently taken up for tablet compression $^{40}$.

Another choice of technique in comparison to spray drying for the high porosity mouth dissolving tablets is the Sublimation method. All the volatile ingredients along with other excipients compressed into tablets to form a porous matrix, this is called the sublimation process. In this technique constituents used are inert in nature like camphor, urea, ammonium bicarbonate, naphthalene etc. The matrix porosity is also caused by the solvents like benzene, cyclohexane etc. ${ }^{41}$ Elbary et al., [2012] developed orodispersible tablets of meloxicam using two methods including sublimation technique and freeze-drying with Ac-Di-Sol as a superdisintegrant and camphor, menthol and thymol as a subliming agent.

Meloxicam is practically insoluble in water (12 $\mu \mathrm{g} / \mathrm{ml})$, its poor solubility and wet ability lead to poor dissolution and hence, variation in bioavailability. The formulation containing the highest percentage of camphor shows the lowest disintegration time and wetting time respectively 9 and $10.1 \mathrm{sec}$. The prepared orally disintegrating tablets break within rare seconds deprived requirement of water, thereby improve the absorption leading to improved bioavailability of meloxicam ${ }^{42}$. 
One approach also employed for mouth dissolving tablets preparation by the practice of polyethylene glycol and methanol blend is incorporation. This solvent system is expulsed by a syringe or a device to get a cylindrical form. This will get cut to sections using an intense blade to form tablets. For taste masking of bitter drugs, this is also used ${ }^{43}$.

Nanonization method is the key process for poorly water-soluble drugs. In this technique particle size of the drug is reduced by the wet media milling procedures. The approach is a water-based media milling process in which nano-sized particles are obtained by the shear fracture of the micron-sized drug particles. Stabilizers are used to prevent the agglomeration of the nano-crystals by surface adsorption. Nanoparticle dispersions are stable and typically have a mean diameter of less than $200 \mathrm{~nm}$ with $90 \%$ of the particles being less than $400 \mathrm{~nm}^{44}$.

Lai et al., [2011] prepared orally disintegrating tablets (ODTs) using nano-crystal technology for the enhancement of dissolution properties of lipophilic, poorly soluble drug piroxicam (PRX). The formulation containing a high degree of poloxamer 188 show the high percent of PRX release from the ODT within $60 \mathrm{~min}^{45}$.

\section{TABLE 2: PATENTED TECHNOLOGIES FOR MOUTH DISSOLVING TABLETS ${ }^{49,50}$}

\begin{tabular}{|c|c|c|c|c|}
\hline S. no. & Technology & Method & Active Moiety & Company \\
\hline 1 & WOWTAB $^{\circledR}$ & Direct compression & Famotidine & $\begin{array}{l}\text { Yamanouchi Pharma Technologies, } 1050 \\
\text { Arastradero Road, Palo Alto, CA, USA }\end{array}$ \\
\hline 2 & ORASOLV $^{\circledR}$ & Direct compression & Paracetamol & $\begin{array}{c}\text { Cima Labs, Inc., } 10000 \text { Valley Hill Road, Eden } \\
\text { Prairies, MN, USA }\end{array}$ \\
\hline 3 & DURASOLV $^{\circledR}$ & Direct compression & Zolmitriptan & $\begin{array}{c}\text { Cima Labs, Inc., } 10000 \text { Valley Hill Road, Eden } \\
\text { Prairies, MN, USA }\end{array}$ \\
\hline 4 & FLASHTAB $^{\circledR}$ & Direct compression & Ibuprofen & $\begin{array}{l}\text { Prographarm, Chaueauneuf- } \\
\text { En-Thymeraia, France }\end{array}$ \\
\hline 5 & LYOC $^{\circledR}$ & Lyophilization & $\begin{array}{l}\text { Phlorglucinol } \\
\text { hydrate }\end{array}$ & $\begin{array}{c}\text { Farmalyoc, 5AV Charles Marting, Maisons- } \\
\text { Alfort, France }\end{array}$ \\
\hline 6 & QUICKSOLV $^{\circledR}$ & Lyophilization & Risperidone & $\begin{array}{l}\text { Janssen Pharmaceutica, } 1125 \text { Trenton- } \\
\text { Harbourton Road, Titusville, NJ, USA }\end{array}$ \\
\hline 7 & ZYDIS $^{\circledR}$ & Lyophilization & Loratidine & R. P. Scherer, Frankland Road, Swindon, UK \\
\hline 8 & FLASHDOSE $^{\circledR}$ & Cotton Candy Process & $\begin{array}{c}\text { Tramodol } \\
\text { hydrochloride }\end{array}$ & $\begin{array}{c}\text { Fuisz Technologies, } 14555 \text { Avion At Lakeside, } \\
\text { Chantilly, VA, USA }\end{array}$ \\
\hline
\end{tabular}

TABLE 3: COMMERCIALLY AVAILABLE MOUTH DISSOLVING TABLET PRODUCTS

\begin{tabular}{|c|c|c|c|c|}
\hline S. no. & Brand Name & Active Agent & Category & Manufacturer \\
\hline 1 & Alavert Quick Dissolving Tablets & Loratadine & Anti-histamines & Wyeth \\
\hline 2 & Benadryl FastMelt & Diphenhydramine & Anti-histamines & Pfizerinc., NY, USA \\
\hline 3 & Claritin RediTabs & Loratadine & Anti-histamines & $\begin{array}{l}\text { Schering-Ploughcorp., } \\
\text { Kenilworth, USA }\end{array}$ \\
\hline 4 & FazaClo & Clozapine & Antipsychotics & Azur Pharma \\
\hline 5 & Feldene fast Melt & Piroxicam & $\begin{array}{l}\text { Anti-rheumatic, non- } \\
\text { steroidal }\end{array}$ & Pfizer inc., NY, USA. \\
\hline 6 & Meloxicam $7.5 \& 15 \mathrm{mg}$ & Meloxicam & NSAIDs & Alpex Pharma (UK) LTD \\
\hline 7 & Mirtazapine ODT & Mirtazapine & Antidepressants & Teva Pharmaceuticals \\
\hline 8 & NurofenMeltlets & Ibuprofen & NSAIDs & Reckitt Benckiser \\
\hline 9 & Risperdal M-Tab & Risperidone & Atypical antipsychotics & Janssen \\
\hline 10 & Romilast & Montelukast & Anti-Allergic & $\begin{array}{c}\text { Ranbaxy Labs, New } \\
\text { Delhi, India }\end{array}$ \\
\hline 11 & Suprenza & Phentermine & Amphetamine & Alpex Pharma /Citius \\
\hline 12 & TorraxMT & Rofecoxib & COX-2 inhibitor & $\begin{array}{l}\text { Torrent Pharma., } \\
\text { Ahmedabad, India }\end{array}$ \\
\hline 13 & VOMETA FT (Flash Tab) & Domperidone & $\begin{array}{c}\text { Antimetics/Prokinetic } \\
\text { Agent }\end{array}$ & Dexamedica \\
\hline 14 & Zofran ODT & Ondansetron & Antiemetics & GlaxoSmithKline \\
\hline 15 & Zoming-ZMT & Zolmitriptan & Anti-migrane & Astra Zeneca, USA \\
\hline 16 & ZyprexaZydis & Olanzapine & Atypical antipsychotics & $\begin{array}{l}\text { Eli Lilly and Company, } \\
\text { Indianapolis, USA }\end{array}$ \\
\hline
\end{tabular}


Apart from all these methods, cotton candy is a unique process. FLASHDOSE ${ }^{\circledR}$ mouth dissolving tablets is manufactured by Shear-form ${ }^{\mathrm{TM}}$ and Ceform TI TM technology. This abolishes the unpleasant sense of taste of active pharmaceutical ingredient 46, 47. 'Floss' is a conjugation of manufacturing excipients lonely or with active pharmaceutical ingredients is developed by Shearform technology. Saccharides such as sucrose, dextrose, lactose, and fructose are used for the preparation of floss which is similar to the cotton candy fibers. For that temperature of $180-266{ }^{\circ} \mathrm{F}$ has been applied ${ }^{48}$. The advantage is that the tablet prepared by this method is porous and upon contact with saliva the sugars get dissolve which feels very pleasant. It is a floss blend; floss processing, floss chopping and conditioning, blending and compression.

Evaluation of Mouth Dissolving Tablets: Mouth dissolving tablets are evaluated for the various parameters like hardness, friability, weight variation, drug content, etc. Apart from these conventional evaluation parameters, there are some specific parameters that are important in order to establish the effectiveness of MDTs for the drug delivery purpose. These parameters include wetting time, disintegration time, dissolution study and moisture uptake study.

The wetting time of the mouth dissolving tablets is very considerable because when we place MDT in the mouth it gets dissolve within a few seconds. Lower wetting time gives very fast disintegration of the MDT, So, it plays an important role in the manufacturing of mouth dissolving tablets. For the assessment of wetting time $10 \mathrm{ml}$ of distilled water containing eosin, a water-soluble dye was placed in a Petri dish of $10 \mathrm{~cm}$ diameter. Tablets were carefully placed in the center of the Petri dish and the time vital for water to touch the higher superficial of the tablet was noted. This is called wetting time ${ }^{51}$.

The disintegration test is also widely employed for MDT's. Disintegration time is measured using the USP disintegration test apparatus. Six tablets per batch are used for disintegration test. The disintegration test is performed in $900 \mathrm{ml}$ simulated saliva fluid $\mathrm{pH} 6.8$ at $37 \pm 0.5{ }^{\circ} \mathrm{C}$ temperature and at the rate of $30 \pm 2$ cycles/min ${ }^{52}$.
A dissolution study is very important for mouth dissolving tablets. In-vitro dissolution study of mouth dissolving tablets is carried out using the tablet dissolution test apparatus (USP XXII type) at $50 \mathrm{rpm}$. Phosphate buffer $\mathrm{pH} 6.8$ is used as the dissolution media and temperature maintained at 37 $\pm 0.5{ }^{\circ} \mathrm{C}$. Samples are withdrawn at different time intervals and analyzed by suitable analytical method $^{53}$

Apart from these mouth dissolving tablets also taken for moisture uptake studies because numerous excipients are hygroscopic in nature. In the desiccator with calcium chloride randomly ten tablets are taken up and reserved at $37^{\circ} \mathrm{C}$ for $24 \mathrm{~h}$. For two weeks the tablets are then weighed and open to $75 \%$ relative humidity at room temperature.

At the bottom of the desiccators, sodium chloride is kept for the attainment of $75 \%$ relative humidity for three days. As a control group, one superdisintegrant deficit tablet is kept for the evaluation of other excipients moisture uptake in the tablet ${ }^{54}$.

CONCLUSION: In the modern era of therapeutics mouth dissolving tablets are widely preferred in the market in comparison to conventional dosage forms like a tablet, capsules. The patient compliance and satisfaction are very important in drug delivery system. Mouth dissolving tablets are cost-effective with the addition of advantage to dysphasic patients as they disintegrate and dissolve in mouth within a few minutes and release active agents. The new technologies of manufacturing provide tablets with rapid onset of action, increased bioavailability, low side effects and better safety.

ACKNOWLEDGEMENT: The author expresses his gratitude to Dr. Navneet Garud Sir, Associate Professor, Department of Pharmaceutics, Jiwaji University for his constant help and support.

CONFLICTS OF INTEREST: The authors declare that they have no conflict of interest.

\section{REFERENCES:}

1. Pandey $\mathbf{P}$ and Dahiya M: Oral disintegrating tablets: A review. International Journal of Pharma Research \& Review 2016; 5: 50-62.

2. Khanna K, Xavier G, Joshi SK, Patel A, Khanna S and Goel B: Fast dissolving tablets-A novel approach. International Journal of Pharmaceutical Research \& Allied Sciences 2016; 5: 311-22. 
3. Allam A and Fetih G: Sublingual fast dissolving niosomal films for enhanced bioavailability and prolonged effect of metoprolol tartrate. Drug design, Development and Therapy 2016; 10: 2421.

4. Irfan M, Rabel S, Bukhtar Q, Qadir MI, Jabeen F and Khan A: Orally disintegrating films: A modern expansion in drug delivery system. Saudi Pharmaceutical Journal 2016; 24: 537-46.

5. Dungarwal UN and Patil SB: Development of orodispersible tablets of taste masked rizatriptan benzoate using hydroxypropyl $\beta$-cyclodextrin. Journal of Pharmaceutical Investigation 2016; 46: 537-45.

6. Ganesh NS and Deshpande KB: Orodispersible tablets: an overview of formulation and technology. International Journal of Pharma and Bio Sciences 2011; 728-29.

7. Maeda $\mathrm{K}$ and Akagi J: Treatment of sarcopenic dysphagia with rehabilitation and nutritional support: a comprehensive approach. Journal of the Academy of Nutrition and Dietetics 2016; 116: 573-7.

8. European Pharmacopoeia: Directorate for the quality of medicines of the council of Europe (EDQM), council of Europe 2002; 2435.

9. Aggarwal P, Nautiyal $U$ and Mali RR: A review on fast dissolving tablet. International Journal of Recent Advances in Science and Technology 2015; 2: 20-8.

10. Masih A, Kumar A, Singh S and Tiwari AK: Fast dissolving tablets: A review. Int J Curr Pharm Res 2017; 9: 8-18.

11. Konar S and Mukhopadhyay A: Fast dissolving drug delivery system A novel approach. International Journal of Pharmacy \& Bio-Sciences 2014; 14: 1.

12. Sharma $S$ : New generation of the tablet: fast dissolving tablet. Latest Rev Pharm info Net 2008; 6.

13. Kumari S, Visht S, Sharma PK and Yadav RK: Fast dissolving Drug delivery system: Review ArticleJournal of Pharmacy Research 2010; 3: 1444-49.

14. Siddiqui MN, Garg G and Sharma PK: Fast dissolving tablets: Preparation, characterization and evaluation: An overview. Int J of Phar Sci Rev and Res 2010; 4: 87-96.

15. Fu Y, Yang S, Jeong SH, Kimura S and Park K: Orally fast disintegrating tablets: Developments, technologies, taste-masking and clinical studies. Critical Reviews ${ }^{\mathrm{TM}}$ in Therapeutic Drug Carrier Systems 2004; 21: 433-76.

16. Dollo G, Chevanne F, Le Corre P, Chemtob C and Le Verge R: Bioavailability of phloroglucinol in man. Journal de pharmacie de Belgique 1999; 54: 75-82.

17. Gafitanu E, Dumistracel I and Antochi S: Formulations and bioavailability of propyphenazone in lyophilized tablets. Revista medico-chirurgicala a Societatii de Medici siNaturalisti din Iasi 1991; 95: 127-28.

18. Kaur T, Gill B, Kumar S and Gupta GD: Mouth dissolving tablets: a novel approach to drug delivery. Int J Cur Pharm Res 2010; 3: 1-7.

19. Srinarong P, Faber JH, Visser MR, Hinrichs WLJ and Frijlink HW: Strongly enhanced dissolution rate of fenofibrate solid dispersion tablets by incorporation of superdisintegrants. European Journal of Pharmaceutics and Biopharmaceutics 2009; 73: 154-61.

20. Rao NGR, Ketan $\mathrm{T}$ and Bala S: Formulation and evaluation of fast dissolving tablets of metoprolol tartrate using natural superdisintegrant. Int $\mathbf{J}$ Pharm and Cli Res 2010; 2 : 40-45.

21. Gajare GG, Bakliwal SR, Rane BR, Gujrathi NA and Pawar SP: Mouth dissolving tablet: an review. Int J Pharm Res and Dev 2011; 6: 280-96.

22. Kumar GP and Nirmala R: Fundamental aspects of superdisintegrants: a concise review. Journal of Global Pharma Technology 2012; 4: 1-12.
23. Kumar VD, Sharma I and Sharma V: A comprehensive review on fast dissolving tablet technology. Journal of Applied Pharmaceutical Science 2011; 1: 50-58.

24. Iurian S, Tomuta I, Bogdan C, Rus L, Tokes T, BarbuTudoran L, Achim M, Moldovan M and Leucuta S: Defining the design space for freeze-dried orodispersible tablets with meloxicam. Drug Development and Industrial Pharmacy 2016; 42: 1977-89.

25. Slavkova $M$ and Breitkreutz J: Orodispersible drug formulations for children and elderly. European Journal of Pharmaceutical Sciences 2015; 75: 2-9.

26. Liew KB, Odeniyi MA and Peh KK: Application of freeze-drying technology in manufacturing orally disintegrating films. Pharmaceutical Development and Technology 2016; 21: 346-53.

27. Naik SB, Venkateswarlu $K$ and Chandrasekhar KB: Formulation and in-vitro evaluation of orodispersible tablets of olanzapine for the improvement of dissolution rate. J Chem Pharm Res 2016; 8: 177-81.

28. Desai PM, Liew CV and Heng PW: Review of disintegrants and the disintegration phenomena. Journal of Pharmaceutical Sciences 2016; 105: 2545-55.

29. Shoukri RA, Ahmedm IS and Shamma RN: In-vitro and in-vivo evaluation of nimesulide lyophilized orally disintegrating tablets. European Journal of Pharmaceutics and Biopharmaceutics 2009; 73: 162-71.

30. Kaur V and Mehara N: A Review on: Importance of Superdisintegrants on Immediate Release Tablets. International Journal of Research and Scientific Innovation 2016; 3: 39-43.

31. Qureshi MS, Zafar F, Ali H, Hameed K, Mallick N, Khan $\mathrm{S}$ and Baloch SA: Superdisintegrant on disintegrant and dissolution. The Professional Medical Journal 2016; 23: 1167-70.

32. Hannan PA, Khan JA, Khan A and Safiullah S: Oral dispersible system: A new approach in drug delivery system. Indian Journal of Pharmaceutical Sciences 2016; 78: 2.

33. Almukainzi M, Araujo GL and Löbenberg R: Orally disintegrating dosage forms. J Pharm Invest 2019; 49: 22943.

34. Lachman L, Lieberman HA and Kanig JL: The theory and practice of industrial pharmacy. $3^{\text {rd }}$ ed., Bankar GS, Anderson NR, Lea \& Febiger 1987; 293-45.

35. Mizumoto T, Masuda $\mathrm{Y}$ and Fukui M: US patent 5, 1996.576, 014.

36. Singh S and Shah D: Development and Characterization of Mouth Dissolving Tablet of Zolmitriptan. Asian Pacific Journal of Tropical Disease 2012; 2: S457-S64.

37. Jain AK, Joshi R, Mohan $P$ and Jain SK: Effective Management of Rheumatoid Arthritis: An Approach for Bioavailability Enhancement of Flurbiprofen. Asi J Bio Res 2016; 2: 127-36.

38. JOSHI R, AKRAM W, Garud N, Dubey A and Bhadkariya $S$ : Development and optimization of orodispersible tablets using solid dispersion of Telmisartan. Journal of Drug Delivery and Therapeutics 2018; 8: 171-78.

39. Indurwade $\mathrm{NH}$, Rajyaguru $\mathrm{TH}$ and Nakhat PD: Novel approach: Fast dissolving tablets. Indian drugs 2002; 39: 405-09.

40. Allen LV, Wang B and Davis JD: US patent 5, 1998.807, 576.

41. Kumar R and Swamy VB: Formulation and in-vitro evaluation of mouth dissolving tablets of labetalol $\mathrm{HCl}$ by sublimation method. Asian Journal of Pharmacy and Technology 2016; 6: 70-80. 
42. Elbary AA, Ali AA and Aboud HM: Enhanced dissolution of meloxicam from orodispersible tablets prepared by different methods. Bulletin of Faculty of Pharmacy, Cairo University 2012; 50: 89-97.

43. Bhaskaran $\mathrm{S}$ and Narmada GV: Rapid dissolving tablet a novel dosage form. Indian Pharmacist 2002; 1: 9-12.

44. Merisko-Liversidge E, Liversidge GG and Cooper ER: Nanosizing: a formulation approach for poorly-watersoluble compounds. European Journal of Pharmaceutical Sciences 2003; 18: 113-20.

45. Lai F, Pini E, Angioni G, Manca ML, Perricci J and Sinico C: Nanocrystals as tool to improve piroxicam dissolution rate in novel orally disintegrating tablets. European Journal of Pharmaceutics and Biopharmaceutics 2011; 79: 552-58.

46. Myers GL, Battist GE and Fuisz RC: PCT patent 9, 1995.534, 2931.

47. Cherukuri SR, Myers GL, Battist GE and Fuisz RC: PCT patent 9, 1995.534, 2901.

48. Cherukuri SR, Myers GL, Battist GE and Fuisz RC: US patent $5,1996.587,172$.

49. Gupta MK, Gupta R, Khunteta A and Swarnkar SK: An overview of novel techniques employed in mouth dissolving drug delivery system. International Journal of Engineering Science and Generic Research 2018; 4: 09-27.

50. Namdev $\mathrm{C}$ and Agrawal S: Formulation and evaluation of mouth dissolving tablets of ondansetron hydrochloride. International Journal of Pharmacy \& Life Sciences 2019; 10.

51. Szakonyi G and Zelkó R: Prediction of oral disintegration time of fast disintegrating tablets using texture analyzer and computational optimization. International Journal of Pharmaceutics 2013; 448: 346-53.

52. Mahmoud AA and Salah S: Fast relief from migraine attacks using fast-disintegrating sublingual zolmitriptan tablets. Drug Development and Industrial Pharmacy 2012; 38: 762-69.

53. Karthikeyan M, Umarul AMK, Megha M and Shadeer PH: Formulation of Diclofenac tablets for rapid pain relief. Asian Pacific Journal of Tropical Biomedicine 2012; 2: S308-S11.

54. Amin AF, Shah TJ, Bhadani MN and Patel MM: Emerging trends in the development of orally disintegrating tablet technology. Pharmainfo Net 2006; 4: 1-30.

How to cite this article:

Joshi R, Garud N and Akram W: Fast dissolving tablets: a review. Int J Pharm Sci \& Res 2020; 11(4): 1562-70. doi: 10.13040/IJPSR. 0975-8232.11(4).1562-70.

All $\odot 2013$ are reserved by the International Journal of Pharmaceutical Sciences and Research. This Journal licensed under a Creative Commons Attribution-NonCommercial-ShareAlike 3.0 Unported License.

This article can be downloaded to Android OS based mobile. Scan QR Code using Code/Bar Scanner from your mobile. (Scanners are available on Google Play store) 